\title{
GFAP-Independent Inflammatory Competence and Trophic Functions of Astrocytes Generated from Murine Embryonic Stem Cells
}

\author{
PHILIPP B. KUEGLER, ${ }^{1,2}$ BETTINA A. BAUMANN,${ }^{1}$ BASTIAN ZIMMER, ${ }^{1}$ SASCHA KELLER, ${ }^{3}$ ANDREAS MARX, ${ }^{3}$ \\ SUZANNE KADEREIT, ${ }^{1}$ AND MARCEL LEIST ${ }^{1 *}$ \\ ${ }^{1}$ Doerenkamp-Zbinden Chair of In Vitro Toxicology and Biomedicine, Department of Biology, University of Konstanz, Konstanz, \\ Germany \\ ${ }^{2}$ Konstanz Research School Chemical Biology, Faculty of Science, University of Konstanz, Konstanz, Germany \\ ${ }^{3}$ Department of Chemistry, University of Konstanz, Konstanz, Germany
}

\section{KEY WORDS}

aquaporin; IL-6; single cell; neuronal support; glutamine synthetase

\section{ABSTRACT}

The directed generation of pure astrocyte cultures from pluripotent stem cells has proven difficult. Generation of defined pluripotent-stem-cell derived astrocytes would allow new approaches to the investigation of plasticity and heterogeneity of astrocytes. We here describe a two-step differentiation scheme resulting in the generation of murine embryonic stem cell (mESC) derived astrocytes (MEDA), as characterized by the upregulation of 19 astrocyte-associated mRNAs, and positive staining of most cells for GFAP (glial fibrillary acidic protein), aquaporin- 4 or glutamine synthetase. The MEDA cultures could be cryopreserved, and they neither contained neuronal, nor microglial cells. They also did not react to the microglial stimulus lipopolysaccharide, while inflammatory activation by a complete cytokine mix (CCM) or its individual components (TNF- $\alpha$, IL1- $\beta$, IFN- $\gamma$ ) was readily observed MEDA, stimulated by CCM, became susceptible to CD95 ligand-induced apoptosis and produced NO and IL-6. This was preceded by NF-kB activation, and up-regulation of relevant mRNAs. Also GFAP-negative astrocytes were fully inflammation-competent. Neurotrophic support by MEDA was found to be independent of GFAP expression. In summary, we described here the generation and functional characterization of microglia-free murine astrocytes, displaying phenotypic heterogeneity as is commonly observed in brain astrocytes. @2011 Wiley Periodicals, Inc.

\section{INTRODUCTION}

Astrocytes are a functionally heterogeneous group of cells that differ in function and phenotype, depending on the local environment or their activation state (Allen and Barres, 2009; Kimelberg, 2004; Kimelberg and Nedergaard, 2010; Matyash and Kettenmann, 2010; Walz, 2000; Wang and Bordey, 2008). They have homeostatic functions and provide neuronal support. In addition, they also play an important role in neurotransmission (Nedergaard et al., 2003), in disease processes (Di Giorgio et al., 2008; Di Giorgio et al., 2007; Eddleston and Mucke 1993; Kimelberg and Nedergaard 2010;
Nagai et al., 2007; Quinlan et al., 2007) and in the brain's host defence (Falsig et al., 2008).

Some aspects of astrocyte plasticity and heterogeneity are difficult to examine in primary astrocytes in vitro. Such cultures are most frequently derived from newborn mice and are usually optimized for homogeneity with respect to GFAP expression. The cells are known to differ significantly from adult astrocytes (Cahoy et al., 2008).

It is nowadays widely accepted that GFAP, the most commonly used phenotypic marker, only labels a subset of astrocytes (Cahoy et al., 2008; Kimelberg, 2004; Walz, 2000; Walz and Lang, 1998). Studies with $\mathrm{GFAP}^{--}$mice showed little alterations of phenotype. Astrocytes were normally distributed and still expressed the intermediate filaments nestin and vimentin (Pekny et al., 1995).

The surface protein GLT-1 marks adult astrocytes and was used to isolate $\mathrm{GFAP}^{+}$and $\mathrm{GFAP}^{-}$astrocytes from brain. GLT-1 ${ }^{+} / \mathrm{GFAP}^{-}$astrocytes showed a global gene expression similar to GLT-1 ${ }^{+} / \mathrm{GFAP}^{+}$astrocytes (Lovatt et al., 2007).

Apart from GFAP, the water transport channel aquaporin-4 (Aqp4), the calcium binding protein S100beta, and glutamine synthetase (GS), an enzyme important for glutamate metabolism and ammonia detoxification in the brain, are frequently used for identification of astrocytes (Hinkle et al., 1997; Nagelhus et al., 1997; Suárez et al., 2002). Recently, Aldh1L1, a member of the aldehyde dehydrogenase family 1 , was described as a potential pan-astroglial marker (Cahoy et al., 2008).

Astrocytes are generally considered a very powerful line of host defence in the brain. After primary recognition of invading pathogens by microglia, astrocytes are activated by their secreted cytokines such as TNF and IL-1 (Falsig et al., 2008). In vitro cultured astrocytes, stimulated with

Additional Supporting Information may be found in the online version of this article.

Grant sponsors: DFG, the Doerenkamp-Zbinden Foundation, FP7 ESNATS of the European Union, the Konstanz Research'School Chemical Biology, RTG1331.

*Correspondence to: Marcel Leist, Doerenkamp-Zbinden Chair of in vitro toxicology and biomedicine, Department of Biology, University of Konstanz, M657
D-78457 Konstanz. E-mail: marcel.leist@uni-konstanz.de 
such cytokines, behave similarly to activated macrophages, and upregulate a variety of inflammatory mediators (Falsig et al., 2006). The study of astrocyte-specific inflammation in primary in vitro cultures is frequently confounded by contamination with microglia, which are difficult to separate during the isolation of astrocytes from brain preparations (Hamby et al., 2006; Saura, 2007).

Differentiation of murine embryonic stem (mESC) cells closely mimics sequential processes of brain development (Abranches et al., 2009; Barberi et al., 2003; Zimmer et al., 2011). Thus, differentiating mESC may provide access to astrocytes of different developmental stages. While the differentiation of neurons from embryonic stem cells is a standard procedure nowadays, the differentiation of astrocytes is less well characterized. Existing protocols mostly generate mixed cell populations with a low percentage of astrocytes (Brüstle et al., 1999; Fraichard et al., 1995; Mujtaba and Rao 2002). Relatively pure cultures have only been obtained by transient transfection of a fluorescent-labeled astrocyte-specific reporter construct (GFAP) and subsequent fluorescent-activated cell sorting of GFP-positive cells (Kamnasaran et al., 2008).

To study astrocytes in greater detail, astroglial cultures would be desirable that closer represent the astrocytic heterogeneity of the brain and would allow the detailed investigation of functional attributes such as inflammatory responses and trophic support. We therefore initiated this study to generate microglia-free cultures containing $\mathrm{GFAP}^{+}$and $\mathrm{GFAP}^{-}$astrocytes. We asked whether such astrocyte cultures differentiated from mESC can perform typical functions of astrocytes, such as inflammatory activation, metabolic conversion of drugs and toxicants as well as trophic support of neurons. We further examined on a single cell level whether there is a correlation between GFAP expression and functional properties of astrocytes.

\section{MATERIALS AND METHODS \\ Maintenance of Murine Embryonic Stem Cell Lines}

The mESC lines [E14.1 and CGR8 (wildtype and stably expressing GFP under EF1alpha-promoter and RFP under tubulin-alpha-1 - promoter (Suter et al., 2006)] were maintained in GMEM containing high glucose $(4.5 \mathrm{~g} / \mathrm{L})$, $10 \%$ fetal bovine serum (FBS; PAA, Pasching, Austria), 2 $\mathrm{mM}$ GlutaMax, $2 \mathrm{mM}$ sodium pyruvate, $2 \mathrm{mM}$ nonessential amino acids, $50 \mu \mathrm{M}$-mercaptoethanol, and 1,000 U/ml LIF. Cells were passaged every other day and fed daily with medium with freshly added LIF $(1,000 \mathrm{U} / \mathrm{mL}$, Millipore, Billerica, MA, USA)(Zimmer et al., 2011).

\section{Differentiation into Astrocytes}

Maintenance cultures were used for differentiation at $80 \%$ confluency. The cells were harvested with trypsin, pelleted and resuspended in N2-medium [DMEM/F12, N2 supplement, $10 \mathrm{ng} / \mathrm{mL} \mathrm{bFGF}, 20 \mathrm{ng} / \mathrm{mL}$ EGF (both
R\&D Systems, Minneapolis, MN)]. Single cells $\left(2 \times 10^{6}\right)$ were seeded into ultralow attachment 6-well plates (Corning Life Sciences, Lowell, MA) in $2 \mathrm{~mL}$ N2-medium. The medium was changed every third day. After 21 days, the obtained cell aggregates (20-50 per well) were plated onto fibronectin-coated ( $1 \mu \mathrm{g} / \mathrm{mL}$; Sigma) dishes in astrocyte differentiation medium (DMEM/F12, $2 \%$ FBS, N2, 2 mM GlutaMax, $50 \mu \mathrm{M} \beta$-mercaptoethanol, $5 \mu \mathrm{g} / \mathrm{mL}$ heparin) and differentiated further for 28 days. The medium was changed every third day.

For replating or cryopreservation, the cells were trypsinized at the end of differentiation, triturated with a 5-mL pipette and filtered through a $100-\mu \mathrm{m}$ cell strainer to yield a single cell suspension. They were then cryopreserved in $1 \mathrm{ml}$ FBS containing $10 \%$ DMSO at $5 \times 10^{6}$ cells per cryotube (Nunc, Thermo Fisher Scientific, Waltham, MA) by freezing over night to $-80^{\circ} \mathrm{C}$ in a freezing container (Nalgene, Thermo Fisher Scientific) and stored in liquid nitrogen. For continued culturing, 20,000 cells $/ \mathrm{cm}^{2}$ were seeded onto fibronectin-coated dishes.

\section{Preparation of Cerebellar Granule Cells}

Cerebellar granule cells (CGC) were prepared as described (Volbracht et al., 1999, 2009). Briefly, cerebella were isolated from postnatal Day $7 \mathrm{BALB} / \mathrm{c}$ mice, dissociated by trypsinization and trituration and plated in BME medium containing $10 \% \mathrm{FBS}, 20 \mathrm{mM} \mathrm{KCl}, 0.5 \mathrm{mM}$ GlutaMax, $100 \mathrm{U} / \mathrm{ml}$ penicillin, and $0.1 \mathrm{mg} / \mathrm{mL}$ streptomycin into cell culture plates at varying densities and with different coatings [poly-L-lysine as positive control (Leist et al., 1997)]. After $45 \mathrm{~min}$, the medium was changed to Neurobasal medium (Invitrogen, Carlsbad, CA) supplemented with $2 \%$ B27, $20 \mathrm{mM} \mathrm{KCl}, 0.5 \mathrm{mM}$ GlutaMax, $100 \mathrm{U} / \mathrm{ml}$ penicillin, and $0.1 \mathrm{mg} / \mathrm{ml}$ streptomycin. For longer observations, $50 \%$ of the medium was changed every third day.

\section{Stimulation Assays}

Stimulation agents were added directly to medium that had been on the cells for a minimum of $24 \mathrm{~h}$. The cells were stimulated with a "complete cytokine mix" (CCM) composed of $10 \mathrm{ng} / \mathrm{mL}$ TNF- $\alpha, 10 \mathrm{ng} / \mathrm{mL}$ IL1- $\beta$, and $20 \mathrm{ng} /$ ml IFN- $\gamma$ or with its single components (Falsig et al., 2004), or with $10 \mu \mathrm{g} / \mathrm{mL}$ lipopolysaccharide (LPS). For IL6 ELISA and the Griess assay, supernatants were collected at designated time points and stored at $-80^{\circ} \mathrm{C}$ until further processing. For the CD95L stimulation experiments, MEDA were pre-stimulated with CCM for $24 \mathrm{~h}$ and incubated in presence of CD95L/Fas-ligand (50 $\mu \mathrm{g} / \mathrm{mL}$, BD Pharmingen, Franklin Lakes, NJ) for $24 \mathrm{~h}$.

\section{Immunofluorescence Staining}

Cells were washed with PBS, fixed with either $4 \%$ formaldehyde in PBS for 10 min or ice-cold $\mathrm{MeOH}$ for 20 min at $-20^{\circ} \mathrm{C}$, permeabilized with $0.1 \%$ Triton $\mathrm{X}-100$ in 
TABLE 1. Gene Expression Levels and Relative Gene Expression Changes of Astrocyte Marker Genes During Differentiation of mESC to MEDA

\begin{tabular}{|c|c|c|c|c|c|c|}
\hline \multirow{2}{*}{$\frac{\text { Gene }}{\text { Symbol }}$} & \multirow{2}{*}{$\begin{array}{c}\text { Corresponding protein } \\
\text { Name }\end{array}$} & \multicolumn{5}{|c|}{ Expression (rel. to Gapdh) ${ }^{\mathrm{a}}$} \\
\hline & & DoD 0 & DoD 21 & DoD 28 & DoD 49 & DoD 49 vs. $0^{\mathrm{b}} \pm \mathrm{SEM}^{\mathrm{d}}$ \\
\hline Gapdh & glycerinaldehyde-P dehydrog ${ }^{c}$ & 1000 & 1000 & 1000 & 1000 & 1 \\
\hline Gfap & glial fibrillary acidic protein & 0.02 & 0.03 & 0.08 & 61 & $2912 \pm 46$ \\
\hline Aqp4 & aquaporin-4 & 0.02 & 0.1 & 0.2 & 37 & $1885 \pm 98$ \\
\hline Slc1A2 & GLT-1, EAAT2 & 0.02 & 0.15 & 2.2 & 20 & $576 \pm 249$ \\
\hline Gjb6 & connexin 30 & 0.05 & 0.3 & 0.2 & 4.9 & $108 \pm 0$ \\
\hline Pla2g7 & PAF-acetylhydrolase ${ }^{c}$ & 0.45 & 2.2 & 3.5 & 54 & $80 \pm 28$ \\
\hline $\mathrm{S} 100 \beta$ & S100beta & 0.02 & 0.03 & 0.08 & 0.6 & $29 \pm 2$ \\
\hline Acta2 & Alpha-actin-2 & 4.5 & 4 & 97 & 177 & $28 \pm 8$ \\
\hline Vim & Vimentin & 27 & 29 & 341 & 741 & $24 \pm 3$ \\
\hline PygB & brain glycogen phosphorylase & 2 & 3 & 5.4 & 44 & $23 \pm 3$ \\
\hline Aldh1L1 & aldehyde dehydrog. $1 \mathrm{~L}^{\mathrm{c}}$ & 0.3 & 2 & 1.1 & 9 & $21 \pm 9$ \\
\hline Slc1A3 & Glast, EAAT1 & 2 & 4.2 & 2.9 & 34 & $14 \pm 4$ \\
\hline ApoE & apolipoprotein E & 159 & 633 & 167 & 2497 & $11 \pm 3$ \\
\hline Glul & glutamine synthetase & 24 & 13 & 20 & 384 & $11 \pm 4$ \\
\hline AldoC & fructose biphosphate aldolase $\mathrm{C}$ & 4 & 5 & 4 & 32 & $7 \pm 0$ \\
\hline Gja1 & connexin 43 & 82 & 90 & 159 & 627 & $6 \pm 1$ \\
\hline Csad & cysteine SA decarbox $^{c}$ & 1 & 3.3 & 0.9 & 8.3 & $5 \pm 2$ \\
\hline BysL & bystin, bystin-like & 4 & 6.4 & 8 & 21 & $4 \pm 1$ \\
\hline Kenj10 & potassium channel Kir4.1 & 0.6 & 0.6 & 0.3 & 2 & $3 \pm 0$ \\
\hline Car2 & carbonic anhydrase 2 & 9.2 & 4.6 & 3.3 & 20 & $2 \pm 0$ \\
\hline Pou5f $1^{\mathrm{e}}$ & 4-Oct & 29 & 10 & 1 & 0.7 & $0.02 \pm 0.01$ \\
\hline Nanoge & nanog homeobox & 2692 & 1110 & 202 & 98 & $0.06 \pm 0.02$ \\
\hline $\mathrm{Nes}^{\mathrm{e}}$ & nestin & 0.1 & 0.2 & 3.5 & 1.5 & $8 \pm 2$ \\
\hline
\end{tabular}

"Gapdh was used as housekeeping gene and its expression was arbitrarily set to 1,000. The expression of all other genes was expressed as $2^{-\lambda C t}$, relative to Gapdh. The $C t$-values above $\geq 35$ were set to 35 . Gapdh $C t$ were mESC 19.5; DoD21 20.1; DoD28 21.4; DoD49 23.4.

Colive

"Abbreviations: Gapdh, glycerinealdehydephosphate dehydrogenase; Pla2g7, platelet-activating factor acetylhydrolase; Aldh1L1, aldehyde dehydrogenase 1 L1; Csad, cyseine sulfinic acid decarboxylase.

Average variation of the upregulation factors for DoD49 vs. DoD0 are displayed for two independent differnentiations.
The pluripotency markers Pou5f1 and Nanog and the neuroectoderm marker Nestin were included for comparison to the astrocyte-specific markers above.

PBS for $10 \mathrm{~min}$, and blocked with $10 \%$ FBS in PBS or $1 \%$ BSA for $30 \mathrm{~min}$. Cells were then stained with primary antibodies and appropriate secondary antibodies (see Supp. Info. Table 1). Nuclei were counterstained with H-33342 (Hoechst dye).

\section{Viability Assays}

For calcein/H-33343 or Sytox/H-33342 staining (Lotharius et al., 2005), the dyes were added to live cells for up to $30 \mathrm{~min}$ before they were imaged (see Supp. Info. Table 1).

\section{Quantitative-RTPCR}

Total RNA was isolated using TRIzol ${ }^{\circledR}$ (Invitrogen) or PeqGold TriFast (Peqlab, Erlangen, Germany) according to the manufacturers' instructions and reverse transcribed to cDNA using Superscript II Reverse Transcriptase (Invitrogen). Quantitative-RT-PCR to measure mRNA expression levels was performed using a MyIQ cycler (BioRad, Hercules, CA) and the Platinum $\mathbb{R}$ SYBR $($ B Green qPCR Supermix kit (Invitrogen) according to the manufacturers instructions. Raw data were processed as described previously (Zimmer et al., 2011). For a list of primers see Supp. Info. Table 1.

\section{Protein Isolation and Western Analysis}

About $10 \mu \mathrm{g}$ of total protein were separated by SDSPAGE and the gels were blotted onto nitrocellulose membranes. The membranes were incubated with primary and secondary antibodies diluted in $2 \%$ milk in TBST (Supp. Info. Table 1). Blots were developed using Pierce $(B)$ ECL Western Blotting Substrate (Thermo Fisher Scientific) and were imaged on a BioRad imaging system (ChemiDOC XRS).

\section{Detection of NO and IL-6}

Nitrite in the supernatant was quantified using the Griess assay (Leist et al., 1995). For detection of IL-6 in the supernatant, a mouse IL-6 ELISA Ready-SET-GO kit (eBioscience, San Diego, CA) was used according to the manufacturers' instructions.

\section{Quantification of MPTP Conversion}

MEDA were incubated with 1-methyl-4-phenyl-tetrahydropyridine (MPTP, Sigma) for $72 \mathrm{~h}$. Then supernatants were sampled and cleared by centrifugation $(20,000 \mathrm{~g}, 20$ $\mathrm{min})$. The method for the detection and quantification of the MPTP metabolite 1-methyl-4-phenylpyridinium $\left(\mathrm{MPP}^{+}\right)$in cell culture supernatant was adapted from Zhang et al., (2008) with the following changes: aliquots (10 $\mu \mathrm{L})$ of thawed supernatants were directly injected into a HPLC-coupled High Resolution ESI-TOF mass spectrometer (Bruker Daltonics micrOTOF II). The retention time of $\mathrm{MPP}^{+}$was identified using a UV-detector that detected $\mathrm{MPP}^{+}$at $295 \mathrm{~nm}$. The desired peaks were automatically further analyzed by mass spectrometry. QuantAnalysis 2.0 Software (Bruker Daltonics) was used for quantification. 


\section{Statistics}

Data are presented as means \pm SEM and the statistical differences were tested by ANOVA with Bonferroni's Multiple Comparison Test post-hoc test, using GraphPad Prism 4.0 (Graphpad Software, La Jolla, CA). Statistical significance was assumed when $P<0.05$, and was indicated by an asterisk on the respective data point in figures.

\section{RESULTS \\ Differentiation of mESC to Highly Astrocyte-Enriched Cultures}

A two-step procedure was developed and optimized to generate murine embryonic stem cell-derived astrocytes (MEDA). The neural induction phase during the first step was based on suspension cultures that were started from single cells. These formed cell aggregates that were grown for 21 days. Cell aggregates were plated onto fibronectin-coated plates and expanded in astrocyte differentiation medium for additional 28 days. During this time the aggregates adhered and cells migrated out, developing a flat transparent morphology resembling primary astrocytes (Fig. 1A). Protein expression analysis of the astrocyte marker GFAP during differentiation revealed a sharp increase in expression during the last week of the adherent culture phase (day of differentiation (DoD) 41-DoD49) (Fig. 1B).

We used a broad panel of genes characterizing astrocytes (Kuegler et al., 2010), to analyze the differentiation kinetics in more detail. All 19 marker genes were upregulated between 3- and 3000-fold (Table 1), while the pluripotency genes coding for Oct-4 and Nanog decreased steadily. Nestin, a marker for neural progenitor cells increased transiently. When astrocytic marker proteins were investigated by immunostaining, we observed high expression of GFAP, Aqp4, glutamine synthetase, and $\mathrm{S} 100 \beta$ in a majority of cells throughout the cultures on DoD49 (Fig. 1C). CNPase, a marker for oligodendrocytes, or beta-III tubulin, a neuronal marker were not detectable (data not shown). Robustness and general applicability of the differentiation protocol was verified with other mESC lines such as E14.1 and subclones of CGR8 (data not shown).

\section{Cytokine Activation of MEDA Cultures}

Following injury, and as a result of other inflammatory signals, astrocytes undergo activation (Blomgren et al., 2007; Falsig et al., 2008). This is commonly modelled in vitro by cytokine stimulation and measurement of the production of key inflammatory mediators. Here, we examined the acquisition of inflammatory competence by MEDA during differentiation, by measuring release of interleukin 6 (IL-6) and nitric oxide (NO) into the culture supernatants. Stimulations were performed with a frequently used 'complete cytokine mix' (CCM) (Falsig et
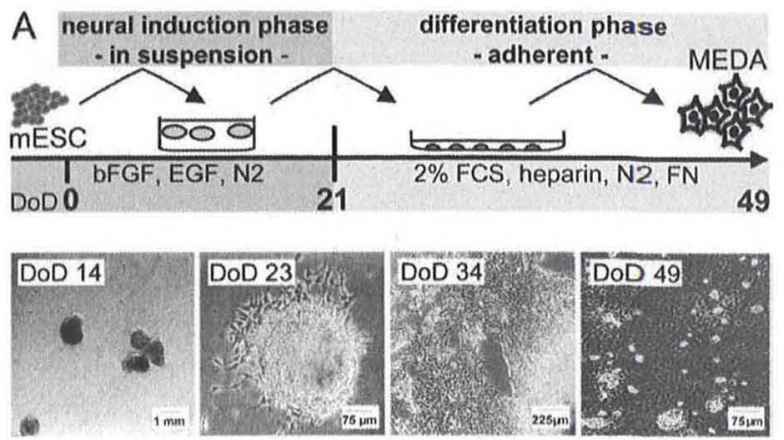

B
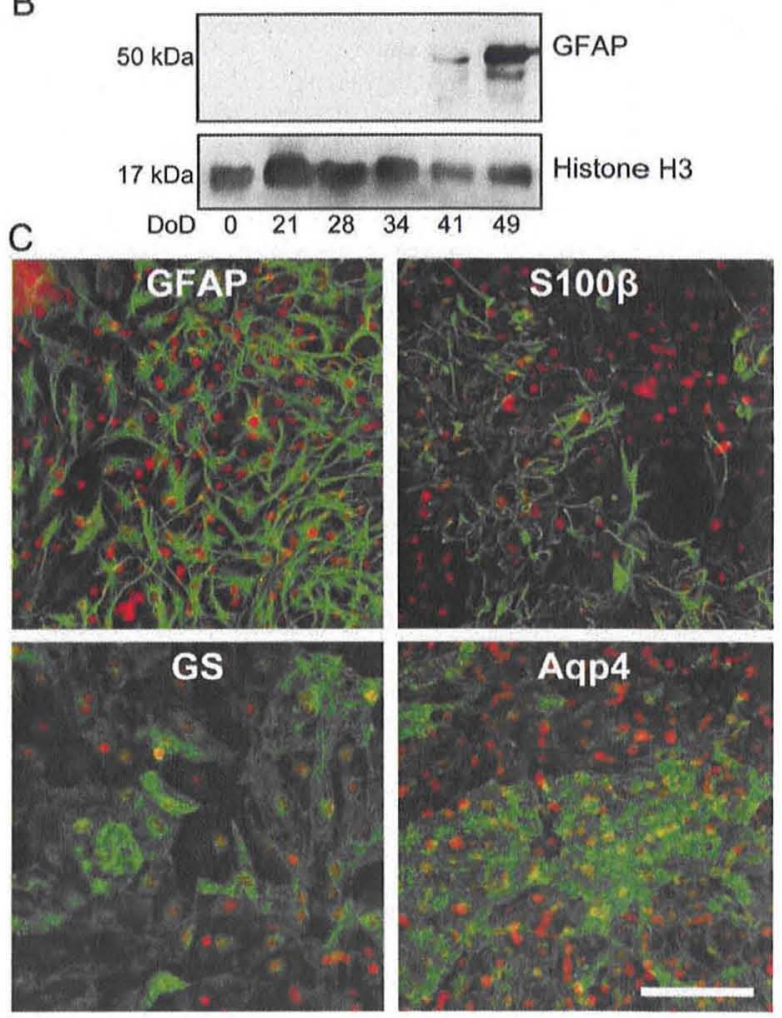

Fig. 1. Differentiation of mESC to MEDA. A: The key steps in the generation of MEDA from mESC are displayed schematically along with the typical morphological appearance of the cultures at selected days of differentiation (DoD). B: During the differentiation process, GFAP expression was assessed by Western Blot. C: On DoD49, the cultures were immunostained for the astrocytic marker proteins (green) GFAP, S100ß, GS, and Aqp4 and counterstained for DNA (red) with H33342. Scale bar $=100 \mu \mathrm{m}$. [Color figure can be viewed in the online issue, which is available at wileyonlinelibrary.com.]

al., 2004; Falsig et al., 2006; Henn et al., 2011), consisting of interleukin 1 beta (IL1- $\beta$ ), interferon gamma (IFN- $\gamma$ ) and tumour necrosis factor alpha (TNF- $\alpha$ ). While pluripotent mESC showed no response to CCM, the response increased steadily from DoD28 onwards in the differentiating cultures. On DoD49, the fully differentiated, CCM-stimulated MEDA secreted high amounts of NO and IL-6 (Fig. 2A), while unstimulated MEDA did not secrete such mediators (not shown). This response 


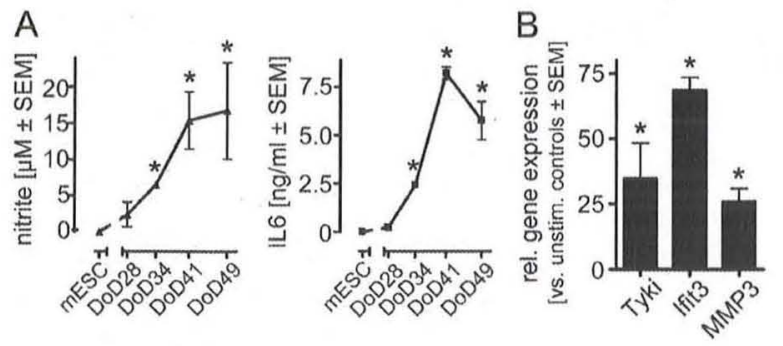

Fig. 2. Differentiation of mESC into inflammation-competent astrocytes. The undifferentiated (mESC) and differentiating cells were stimulated at different stages (DoD) with a "complete cytokine mix" (CCM), comprising TNF- $\alpha$ (10 ng/mL), IL1- $\beta$ (10 ng/mL), and IFN- $\gamma$ (20 $\mathrm{ng} / \mathrm{mL}$ ) for $24 \mathrm{~h}$, and the release of NO and IL-6 into the supernatant was measured. B: MEDA were stimulated on DoD49 with CCM for 16 $h$ before RNA expression was analyzed by qPCR for the astrocyte inflammation markers Cmpk2 (Tyki), Ifit3, and Mmp3. Data represent means \pm SEM from three independent differentiations. ${ }^{*} P<0.05$ (vs. mESC (A), vs. unstimulated control (B)).

was similar to that of primary astrocytes (Falsig et al., 2004, 2006; Henn et al., 2011). MEDA stimulated on DoD49 (Supp. Info. Fig. 1A) also upregulated other typical astrocyte inflammation markers (Crocker et al., 2008; Falsig et al., 2004; Henn et al., 2011), such as Cmpk2 (Tyki), Ifit 3 and matrix metalloprotease 3 (Mmp3) after stimulation (Fig. 2B).

\section{Replated MEDA Cultures with Different Subpopulations}

For the use of MEDA in inflammation studies, reproducible cell numbers and similar cell populations across multiple wells are desirable. This was achieved by large scale differentiation, and subsequent replating at defined cell numbers. After replating, such secondary cultures were phenotyped and used for all further functional experiments (Supp. Info. Fig. 1B). Immunofluorescence microscopy revealed several subpopulations. While most cells $(81 \pm 16 \%)$ expressed $\mathrm{S} 100 \beta$ protein (Fig. 3A, Supp. Info. Fig. $2 A$ ), $31 \pm 18 \%$ of the cells were GFAPpositive (Fig. 3B, Supp. Info. Fig. 2B). In addition, many of the GFAP-negative cells were positive for other astrocytic markers such as glutamine synthetase (Fig. 3C, Supp. Info. Fig. 2C) or Aqp4 (Fig. 3D, Supp. Info. Fig. $2 D)$. These results suggest the presence of different astrocyte subpopulations, including GFAP-negative astrocytes.

\section{Microglia-Free MEDA Cultures For Inflammation Studies}

Generation of microglial precursor cells from murine embryonic stem cells has recently been described under neural-inductive conditions, and via nestin-postive intermediate stages (Napoli et al., 2009). Therefore, we examined the potential presence of microglial cells. However, we never detected the microglial markers CD11b and F4/80 in MEDA in immunofluorescence microscopy (data
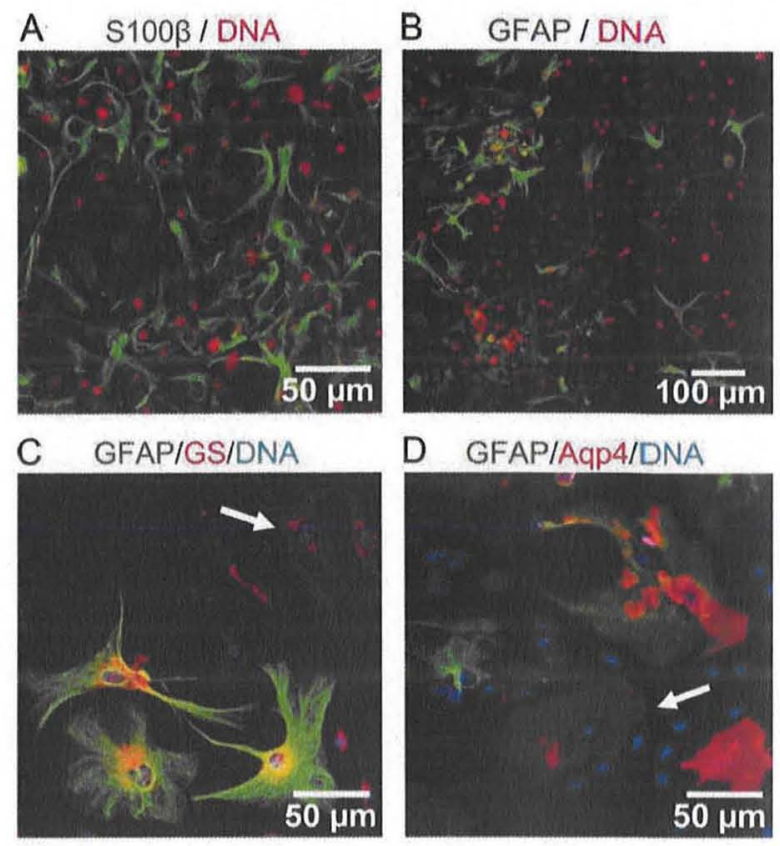

D GFAPIAqP4/DNA
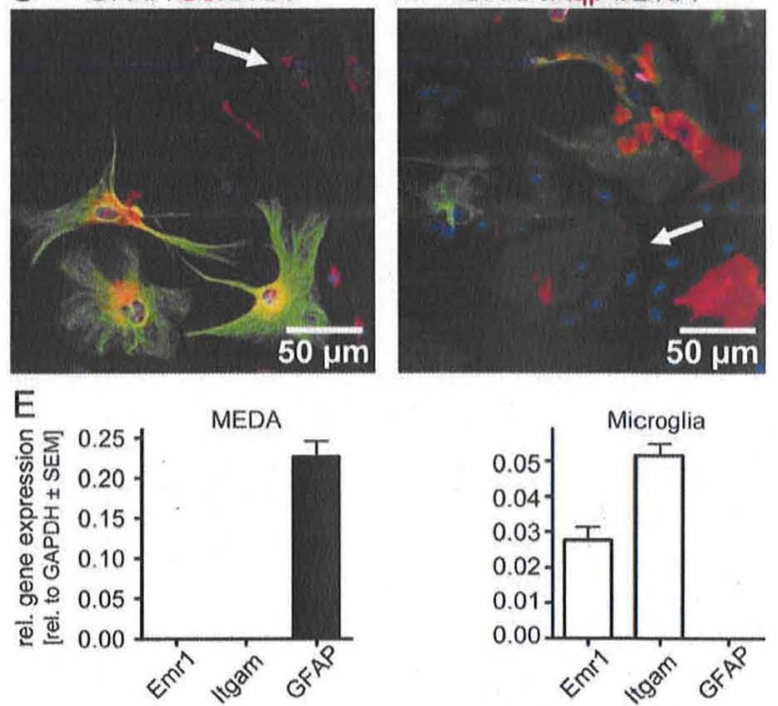

Fig. 3. Characterization of GFAP-negative cells in replated MEDA cultures by other astrocyte markers. MEDA were differentiated and replated at a density of $2 \times 10^{5}$ cells $/ \mathrm{cm}^{2}$. The cultures were immunostained for astrocyte markers $48 \mathrm{~h}$ after passaging, and nuclei were labelled with $\mathrm{H}-33342$. A. The majority of the cells stained positive for S100P (green); B: GFAP staining (green) indicated the presence of presence of C,D: Costaining of GFAP (green) with Aqp4 or GS (red) indicated several subpopulations of cells. Some were double positive; others (arrows indicate examples) were negative for GFAP and positive for other astrocyte markers. Single channel images are provided in Supp. Info. Fig. 2. E: Total RNA was prepared from secondary MEDA cultures $48 \mathrm{~h}$ after replating. Control-RNA was prepared from microglia, and all samples were analyzed for the and Itgam (CD11b). Data are means \pm SEM from three experiments. [Color figure can be viewed in the online issue, which is available at wileyonlinelibrary.com.]

not shown), nor did we detect expression of two microglial marker genes, Emr1 (F4/80) and Itgam (CD11b) by quantitative RT-PCR (Fig. 3E).

Microglia are functionally characterized by their sensitive inflammatory reaction to lipopolysaccharide (LPS), while primary (Passage 1) astrocyte cultures devoid of microglial contamination do not respond to LPS (Falsig et al., 2004; Henn et al., 2011). As NF-kB translocation is a sensitive readout for LPS stimulation on a single cell level (Lund et al., 2005), we examined this response in MEDA and detected no NF-kB translocation in response to LPS stimulation (Supp. Info. Fig. 3). We also 

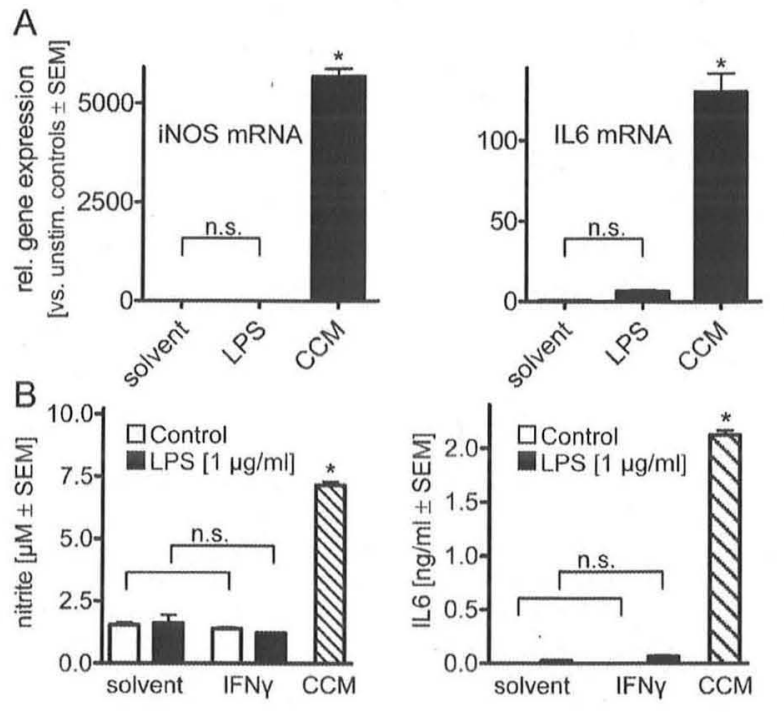

Fig. 4. Inflammatory activation of MEDA cultures by CCM but not by LPS. A: Replated MEDA were stimulated with the microglial stimulant LPS $(1 \mu \mathrm{g} / \mathrm{mL})$, solvent control or an astrocyte-stimulating proinflammatory cytokine mix (CCM) for $16 \mathrm{~h}$, before mRNAs for inducible nitric oxide synthetase (iNOS) and IL-6 were analyzed by qPCR. B Replated MEDA were stimulated with CCM or with LPS in the presence or absence of IFN- $\gamma(20 \mathrm{ng} / \mathrm{mL})$ for $16 \mathrm{~h}$. Nitrite and IL-6 were determined in the supernatant. All data are means + SEM from three experiments. n.s., no significant difference $(P>0.05) ;{ }^{*} P<0.05$.

compared the response of MEDA to LPS and CCM. Increased mRNA levels for inducible nitric oxide synthetase (iNOS) and IL-6 were observed after stimulation with CCM for $16 \mathrm{~h}$, but not after stimulation with LPS (Fig. 4A). This suggests that contaminations, even with small functional microglia subpopulations can be excluded. This was further confirmed when IL-6 and NO secretion were used as physiological response endpoints. Co-administration of IFN- $\gamma$, which is a potential enhancer of LPS responses, also had no effect (Fig. 4B).

\section{Cryopreservation of Functional MEDA}

Cryopreservation of MEDA cultures would facilitate their wide-spread use and comparability between experiments. Therefore, MEDA were cryopreserved on DoD49 by standard methods and the cultures were characterized as described above (also see Supp. Info. Fig. 1B). Viability after thawing was $>90 \%$ for different batches ( $n$ $=10$ ). CCM-stimulated cultures released NO and IL-6 in similar amounts and with similar kinetics as freshly replated cells, while nonstimulated cells remained quiescent after thawing (Supp. Info. Fig. 4A). In order to get more detailed information on the functional capacity of thawed MEDA, they were stimulated with all single constituents of CCM and combinations thereof. The response pattern and the strong synergy of the cytokines (Supp. Info. Fig. 4B) were similar to the one described earlier for primary murine astrocytes (Falsig et al., 2004, 2006; Henn et al., 2011). In a similar manner,
A
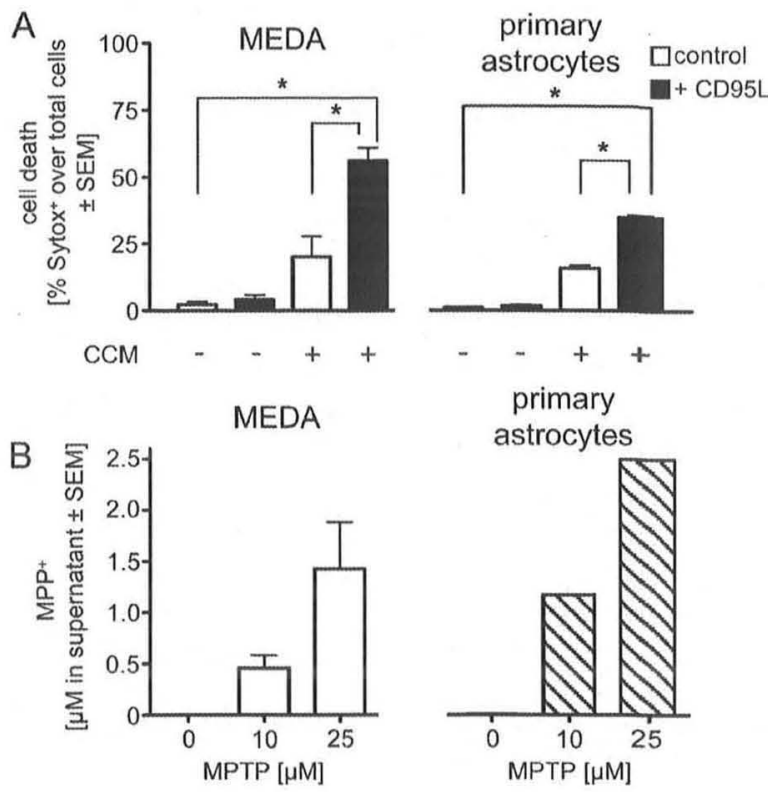

Fig. 5. Astrocyte-specific functional properties of MEDA. A: Cells were stimulated for $24 \mathrm{~h}$ with CCM and exposed to CD95L (FasL) for $24 \mathrm{~h}$. FasL-induced cell death was quantified by co-staining with Sytox (dead cell marker) and $\mathrm{H}-33342$, and counting of live and dead cells.
Data are means \pm SEM of triplicates. $* P<0.05$. B: MEDA were incuData are means \pm SEM of triplicates. ${ }^{*} P<0.05$. B: MEDA were incu-
bated with MPTP for $72 \mathrm{~h}$. Conversion of MPTP to MPP ${ }^{+}$by astrocytes was measured in the supernatant using quantitative HPLC-ESI-TOFMS. Data are means \pm SEM of two independent differentiations. Primary murine astrocytes were used once for comparison.

MEDA developed sensitivity to CD95L after previous inflammatory stimulation, as reported for primary astrocytes (Falsig et al., 2004) (Fig. 5A). Thus, functions and regulations relevant for inflammatory activation of primary astrocytes seem to be active in MEDA, even after freezing and thawing.

To investigate also the capacity of MEDA to metabolize drug-like compounds after thawing, we examined the conversion of nontoxic methylphenyltetrahydropyridine (MPTP) into its neurotoxic metabolite methylphenylpyridinium $\left(\mathrm{MPP}^{+}\right)$and compared the conversion rate with primary astrocytes. This metabolic function of brain astrocytes is the basis for the frequently used MPTP model of Parkinsonian dopaminergic neurodegeneration. As both cell types converted MPTP into MPP ${ }^{+}$ within $72 \mathrm{~h}$ at comparable levels (Fig. 5B), we conclude that MEDA thawed from cryopreservation retained the capacity to metabolize this xenobiotic.

\section{Evidence For Inflammatory Activation of MEDA on the Single Cell Level}

To provide a basis for the study of the inflammatory activation of astrocyte subpopulations, we chose translocation of the pivotal inflammation-activated transcription factor NF-kB from the cytoplasm into the nucleus as read-out. NF-kB is expressed constitutively and resides in the cytoplasm of resting cells (Fig. 6A, Supp. 

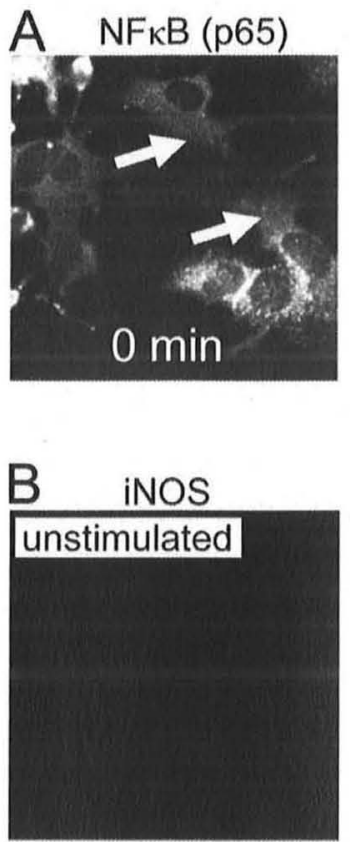

iNOS

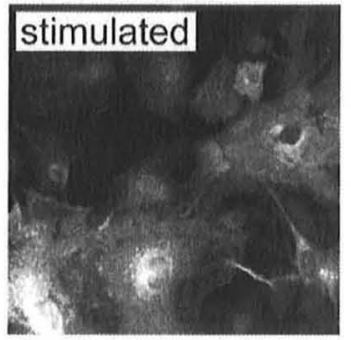

Fig. 6. Characterization of inflammatory activation of MEDA on single cell level. MEDA were used $48 \mathrm{~h}$ after plating. A: The cultures were stimulated with CCM for $1 \mathrm{~h}$ and stained for the p65 subunit of NF-kB. Arrows indicate NF-kB staining in the cytosol, arrowheads point to nuclear NF-kB staining. Nuclear translocation of NF-kB of activated

Info. Fig. 3). The time course of translocation following CCM stimulation was studied. After $15 \mathrm{~min}$, the majority $(90 \pm 2 \%)$ of all cells stained positive for nuclear NF$\mathrm{kB}$ (Fig 6A). Then, relocation to the cytosol started, and after 60 min $50 \pm 4 \%$ of the cells stained for nuclear NF-kB. We chose inducible nitric oxide synthetase (iNOS/NOS2) as second inflammation marker measurable on single cell level. MEDA cultures stimulated with CCM for $24 \mathrm{~h}$ were immunostained for iNOS. The percentage of iNOS expressing cells reached $70 \pm 12 \%$ (Fig. $6 \mathrm{~B})$. Costaining with $\mathrm{S} 100 \beta$ confirmed that the iNOSpositive cells were astrocytes (data not shown).

\section{Neuronal Support Function by GFAP-Positive and GFAP-Negative MEDA}

As support of developing neurons is an important astrocytic function, we tested this potential feature of
MEDA. Primary murine cerebellar granule cells (CGC) were seeded in the presence or absence of a confluent layer of MEDA, and were allowed to mature for at least six days. Neurons formed dense and branched networks, when plated on poly-L-lysine (not shown), but did not survive in the absence of coating. When plated on uncoated plastic covered with a layer of MEDA, a complex neuronal network developed within 6 days after plating (Fig. 7A), while a layer of 3T3 fibroblasts did not support neurons (not shown).

We reduced the standard CGC plating density 25-fold to $10^{4}$ cells $/ \mathrm{cm}^{2}$. This allowed the formation of single, isolated neurons that survived well on MEDA as shown by immunostaining for the neuronal marker Tubb3 (Fig. 7B). The neurons grew on top of the MEDA cells with axons spanning the intercellular space (Fig. 7C). In the absence of MEDA, no live neuron was detectable in these low density neuronal cultures, whether they were coated with poly-L-lysine or not. 

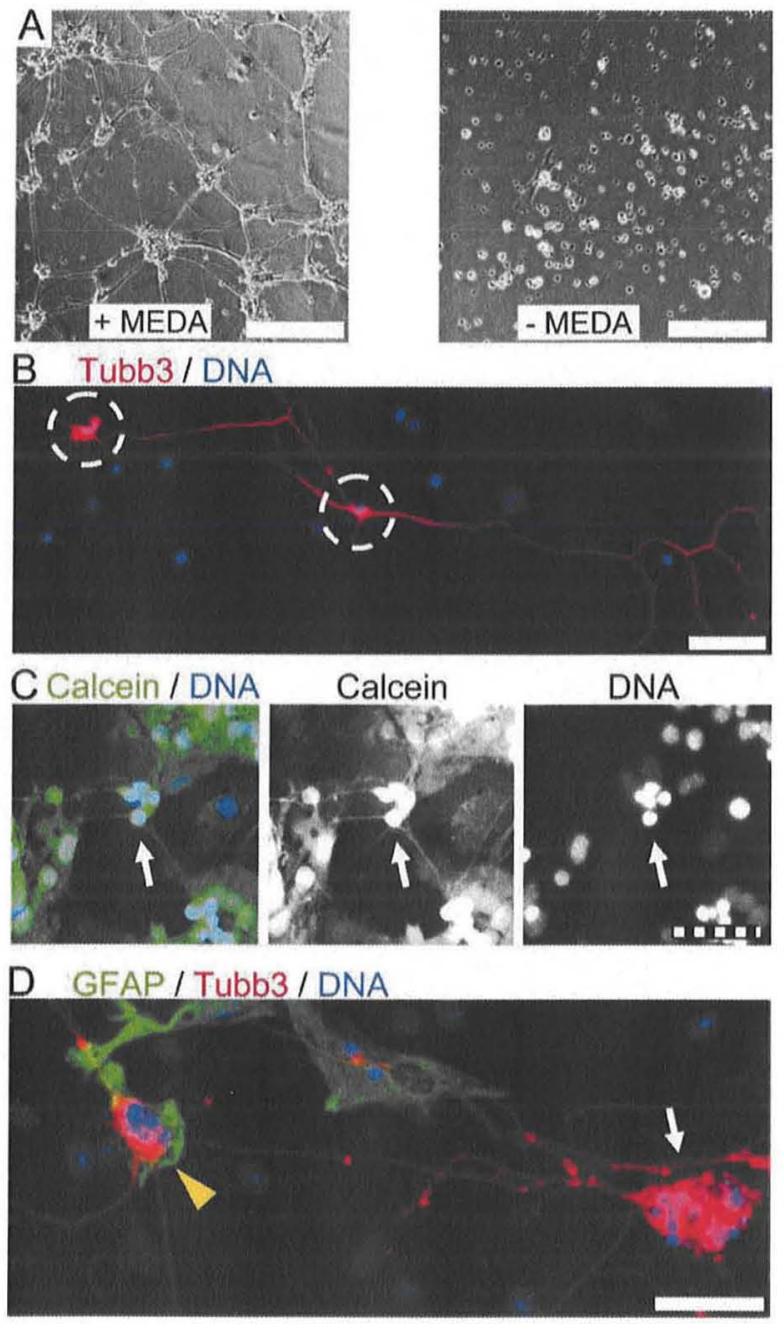

Fig. 7. Neurosupportive properties of GFAP-positive and GFAP-negative MEDA. Cerebellar granule cells (CGC) were plated at suboptima $\left(10,000\right.$ cells $\left./ \mathrm{cm}^{2}\right)$ or optimal $\left(250,000 \mathrm{cells} / \mathrm{cm}^{2}\right)$ density in untreated cell culture dishes or in dishes containing a confluent layer of MEDA. A: After six days in low density culture the CGC had formed a neuronal network on top of MEDA while no neurons survived in the absence of MEDA. B: The neuron-MEDA cocultures were immunostained for the neuronal marker Tub3 3 and nuclei were labelled with the neuronal marker Tubb3, and nuclei were labelled with H-33342. CGC preferably grew as single neurons on top of MEDA cells (white circles) and were connected by long neurites. C: Live cells were labelled with calcein (green), and nuclei were counterstained with H-33342 (blue). The arrow points to individual neurons growing on top of MEDA. Neurons appeared as particularly bright cells. D: The cultures were immunostained for GFAP (green) and Tubb3 (red), and nuclei were labelled with H-33342 (blue). CGC were identified both on GFAPpositive (yellow arrowhead) and on GFAP-negative MEDA (arrow) positive (yellow arroweas) in the online issue, which is available at wileyonlinelibrary.com.]

Attachment of CGC to MEDA was independent of their subtype as neurons survived both on GFAP-positive and GFAP-negative cells (Fig. 7D). Interestingly, neurons on MEDA survived for longer than three weeks, while CGC grown under standard conditions on poly-L-lysine generally lose viability after two weeks in culture.

\section{Inflammatory Competence of GFAP-Positive and GFAP-Negative MEDA Subpopulations}

After our observation that GFAP-negative MEDA provided neuronal support, we also addressed the question whether this subpopulation can also be activated by cytokines to a similar degree as GFAP-positive cells. We studied NF-kB translocation in individual CCM-activated MEDA. Both, GFAP ${ }^{+}$as well as $\mathrm{GFAP}^{-} / \mathrm{Aqp}^{+}$ MEDA showed nuclear NF-kB staining (Fig. 8A,B). Thus, GFAP expression was not required for an initial inflammatory signal transduction of MEDA. Furthermore, we tested whether this also applied to more downstream cellular responses, such as the expression of iNOS. We found that both GFAP-positive and GFAP-negative $\left(\mathrm{S} 100 \beta^{+}\right) \mathrm{MEDA}$ were positive for iNOS $24 \mathrm{~h}$ after stimulation by CCM (Fig. 8C). Thus, it appears likely that all MEDA subpopulations, in particular GFAP-positive and GFAP-negative MEDA, contribute to the production of inflammatory mediators.

\section{DISCUSSION}

A particular aim of our study was to derive astrocyte cultures from mESC that are useful for inflammation studies and that represent a broad variety of astrocyte subpopulations. We identified here GFAP-positive and GFAP-negative subpopulations of MEDA. A subpopulation of cells with astrocytic markers, but without GFAP expression, was capable of an inflammatory response, similar to the one of the well-characterized GFAP-positive astrocytes. Only few papers describe the generation of astrocytes from pluripotent stem cells (ESC or induced pluripotent cells (iPSC)). For example, Mujtaba and Rao generated astrocyte precursor cells from embryonic stem cells by sequential immunopanning and magnetic bead sorting (Mujtaba and Rao, 2002). These progenitors were matured further to astrocytes. Using a further optimization of this approach, Kamnasaran et al., describe the generation of astrocytes from mESC (Kamnasaran et al., 2008). However, the final astrocyte populations were restricted to a strongly GFAP-positive subpopulation.

Astrocyte cultures may also be generated from more committed tissue-specific stem cells, such as neural stem cells isolated from the rodent brain (Crocker et al., 2008; Gritti et al., 1994; Reynolds and Weiss, 1992; Vanhoutte et al., 2004). To our knowledge, little information is available on such cultures concerning the degree of maturity, the dependence on the cell source (age, brain region, isolation, and culture procedure) and the heterogeneity with respect to astrocyte subpopulations.

Primary neonatal astrocytes differ from adult astrocytes and may only reflect a small subpopulation of astrocytes in the brain (Cahoy et al., 2008). Usually, the majority of the cells from primary astrocyte cultures are GFAP-positive. However, in the adult brain GFAP-negative astroglial populations have been reported in several studies (Cahoy et al., 2008; Lovatt et al., 2007). For 
instance, in the adult rat brain, GFAP negative astrocytes constitute $40 \%$ of the entire astrocytic population (Walz and Lang, 1998). Therefore, the contribution of the different subtypes to brain inflammation cannot be studied in standard primary cultures.
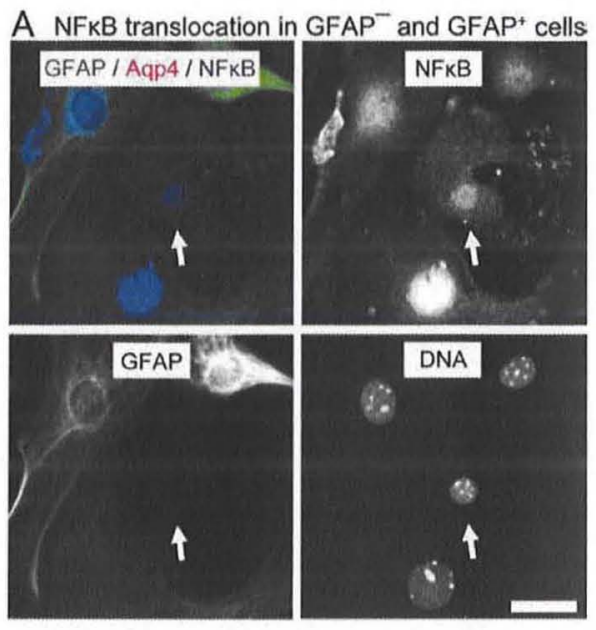

B

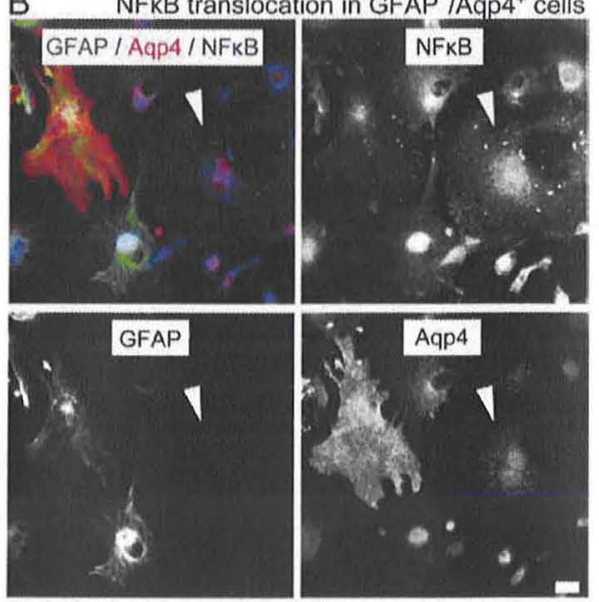

C iNOS induction in GFAP $^{-}$and $\mathrm{GFAP}^{+}$cells
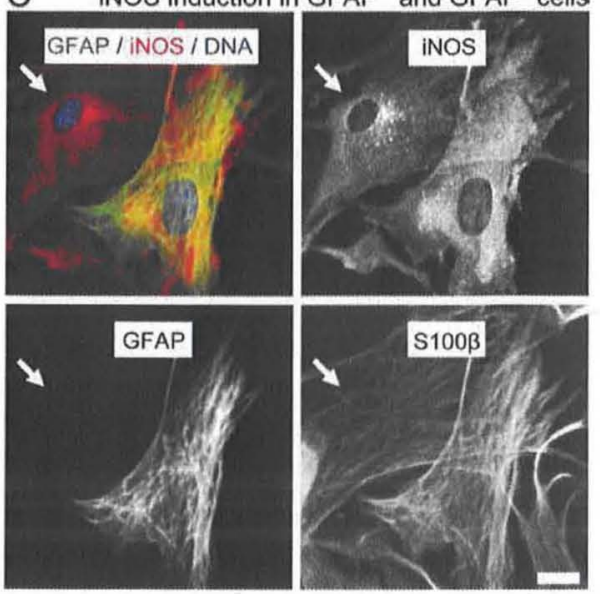

Replating of MEDA facilitated the quantitative phenotyping by immunocytochemistry. Most of the replated or thawed MEDA stained positive for $\mathrm{S} 100 \beta(81 \pm 16 \%)$. These cells contained an astrocytic $\mathrm{GFAP}^{+}$subpopulation $(31 \pm 18 \%)$, of which $19 \pm 13 \%$ also expressed Aqp4. In the $\mathrm{GFAP}^{-}$subpopulation, $15 \pm 10 \%$ were positive for Aqp4. The relative amount of $\mathrm{GFAP}^{+}$cells was higher in the nonreplated DoD49 cultures (Fig. 1C), but exact quantification was difficult because the cells had grown into a tissue-like multilayer before they were trypsinized

Neurons, microglia or oligodendrocytes were undetectable after replating as assessed by immunofluorescence staining and qPCR for RNA expression. Similarly, no remaining pluripotent stem cells were observed, but a subpopulation of other nonastrocytic cells cannot be excluded. A minor proportion of the cells did not stain positive for any marker tested.

Inflammatory activation is one of the most prominent plastic changes of astrocytes, and primary astrocyte cultures have been used in many studies to examine mechanisms of inflammation (Ambrosini et al., 2003; John et al., 2005; Meeuwsen et al., 2003). When stimulated with CCM, MEDA reacted similar to primary astrocytes.

Astrocytes may affect neuronal viability by metabolic conversion of endogenous compounds and xenobiotics. A prominent example is the generation of the toxic metabolite $\mathrm{MPP}^{+}$from MPTP via a reaction catalyzed by monoamine oxidase (MAO) (Aschner and Kimelberg, 1991; Chiba et al., 1984; Marini et al., 1989). As we have shown here, MEDA have a conversion activity similar to primary astrocytes. It may thus be possible to use them in cocultures with dopaminergic neurons to examine metabolism-dependent toxicity of MPTP and other compounds (Schildknecht et al., 2009).

GFAP is the most frequently used marker for inflammatory activation of astrocytes in the brain, and for astrogliosis under pathological circumstances. Frequently, the astrocyte population is defined exclusively by staining for GFAP (Walz 2000). Therefore, data on GFAP-negative astrocytes, and in particular on their inflammatory reaction, are scarce. Most data come from $\mathrm{GFAP}^{-1-}$ mice. These animals can develop reactive gliosis similarly to wild-type animals (Pekny et al., 1995). GFAP expression is thus no absolute prerequisite for inflammatory competence, but it is not clear from these studies, how the normal GFAP-negative subpopulation behaved, and which subpopulation reacted with gliosis.

Fig. 8. Inflammatory activation of GFAP-positive and GFAP-negative MEDA. MEDA were replated on DoD49. A,B: After $48 \mathrm{~h}$, the cultures were stimulated with CCM for $15 \mathrm{~min}$ and immunostained for the p65 subunit of NF-kB and the astrocyte markers GFAP (green) and Aqp4 (red). A: NF-kB translocating GFAP ${ }^{+} /$Aqp $^{-}$MEDA and NF-kB translocating $\mathrm{GFAP}^{-} / \mathrm{Aqp4} 4^{-}$MEDA (arrow). B. NF-kB translocating translocating GFAP (1) MEDA (arrowhead). C: MEDA were stimulated with CCM for $24 \mathrm{~h}$ and immunostained for inducible nitric oxide synthetase (iNOS, red) and the astrocyte markers GFAP (green) and $\mathrm{S} 100 \beta$. A GFAP $/ \mathrm{iNOS}^{+}$cell is shown next to a GFAP ${ }^{-} /$iNOS $^{+}$MEDA cell (arrow). Scale bar $=20 \mu \mathrm{m}$. [Color figure can be viewed in the online issue, which is available at wileyonlinelibrary.com.] 
MEDA cultures allowed us to show here, that activation of the NF-kB pathway in astrocytes upon a proinflammatory stimulus occurs also in the GFAP-negative subpopulation. Furthermore, iNOS was upregulated similarly in GFAP-negative and GFAP-positive MEDA. Thus, not only the GFAP-expressing astrocyte population was inflammation competent. These data suggest that, as in our study, a combination of astrocyte markers (e.g. Aqp4, GFAP and S100ß) may be useful to also detect subpopulations of astrocytes. This would also apply to brain tissue, as already described by Heinrich et al. (2010).

In summary, we established microglia-free cultures of mouse embryonic stem cell-derived astrocytes. The possibility to generate different subpopulations allows studies of astrocyte development and plasticity not possible with other culture models. More advanced protocols may in the future allow the generation of different pure subpopulations, and facilitate studies examining the factors controlling their differentiation. In addition, we showed that cocultures of neurons with MEDA are feasible. This opens up new possibilities of studying the interplay of neurons and astrocytes during development, the influence of astrocytemediated inflammation on neurons or the role of astrocytes for the generation of (developmental) neurotoxicity.

\section{ACKNOWLEDGMENTS}

The authors thank K H Krause, Geneva, Switzerland for the CGR8 cell lines.

\section{REFERENCES}

Abranches E, Silva M, Pradier L, Schulz H, Hummel O, Henrique D, Bekman E. 2009. Neural differentiation of embryonic stem cells in vitro: A road map to neurogenesis in the embryo. PLoS One 4:e6286.

Allen NJ, Barres BA. 2009. Neuroscience: Glia-More than just brain Allen NJ, Barres BA. 2009.
glue. Nature 457:675-677.

Ambrosini E, Columba-Cabezas S, Serafini B, Muscella A, Aloisi F. 2003. Astrocytes are the major intracerebral source of macrophage inflammatory protein-3alpha/CCL20 in relapsing experimental autoimmune encephalomyelitis and in vitro. Glia 41:290-300

Aschner M, Kimelberg HK. 1991. The use of astrocytes in culture as model systems for evaluating neurotoxic-induced-injury. Neurotoxicology 12:505-517.

Barberi T, Klivenyi P, Calingasan NY, Lee H, Kawamata H, Loonam K, Perrier AL, Bruses J, Rubio ME, Topf N, et al. 2003. Neural subtype specification of fertilization and nuclear transfer embryonic stem cells and application in parkinsonian mice. Nat Biotechnol 21:1200-1207.

Blomgren K, Leist M, Groc L. 2007. Pathological apoptosis in the developing brain. Apoptosis 12:993-1010

Brüstle O, Jones KN, Learish RD, Karram K, Choudhary K, Wiestler OD, Duncan ID, McKay RD. 1999. Embryonic stem cell-derived glial precursors: A source of myelinating transplants. Science 285:754-756.

Cahoy JD, Emery B, Kaushal A, Foo LC, Zamanian JL, Christopherson KS, Xing Y, Lubischer J, Krieg PA, Krupenko SA et al 2008. A transcriptome database for astrocytes, neurons, and oligodendrocytes: A new resource for under
J Neurosci 28:264-278.

J Neurosci 28:264-278.
Chiba K, Trevor A, Castagnoli NJ. 1984. Metabolism of the neurotoxic tertiary amine, MPTP, by brain monoamine oxidase. Biochem Biophys Res Commun 120:574-578.

Crocker SJ, Frausto RF, Whitton JL, Milner R. 2008. A novel method to establish microglia-free astrocyte cultures: Comparison of matrix metalloproteinase expression profiles in pure cultures of astrocytes and microglia. Glia 56:1187-1198.

Di Giorgio FP, Boulting GL, Bobrowicz S, Eggan KC. 2008. Human embryonic stem cell-derived motor neurons are sensitive to the toxic effect of glial cells carrying an ALS-causing mutation. Cell Stem Cell 3:637-648

Di Giorgio FP, Carrasco MA, Siao MC, Maniatis T, Eggan K. 2007 Non-cell autonomous effect of glia on motor neurons in an embryonic stem cell-based ALS model. Nat Neurosci 10:608-614.

Eddleston M, Mucke L. 1993. Molecular profile of reactive astrocytes-Implications for their role in neurologic disease. Neuroscience 54:15-36.

Falsig J, Latta M, Leist M. 2004. Defined inflammatory states in astrocyte cultures: correlation with susceptibility towards CD95-driven apoptosis. J Neurochem 88:181-193.

Falsig J, Pörzgen P, Lund S, Schrattenholz A, Leist M. 2006. The inflammatory transcriptome of reactive murine astrocytes and implications for their innate immune function. J Neurochem 96:893-907.

Falsig J, van Beek J, Hermann C, Leist M. 2008. Molecular basis for detection of invading pathogens in the brain. $J$ Neurosci Res 86:1434-1447.

Fraichard A, Chassande O, Bilbaut G, Dehay C, Savatier P, Samarut J. 1995. In vitro differentiation of embryonic stem cells into glial cells and functional neurons. J Cell Sci 108:3181-3188

Gritti A, Parati EA, Cova L, Frolichsthal P, Galli R, Wanke E, Faravelli L, Morassutti DJ, Roisen F, Nickel DD, et al. 1994. Multipotential stem cells from the adult mouse brain proliferate and self-renew in response to basic fibroblast growth factor. J Neurosci 16:1091-100.

Hamby ME, Uliasz TF, Hewett SJ, Hewett JA. 2006. Characterization of an improved procedure for the removal of microglia from confluent monolayers of primary astrocytes. J Neurosci Methods 150:128-137.

Heinrich C, Blum R, Gascón S, Masserdotti G, Tripathi P, Sánchez R, Tiedt S, Schroeder T, Götz M, Berninger B. 2010. Directing astroglia from the cerebral cortex into subtype specific functional neurons. PLos Biol 8:e1000373.

Henn A, Kirner S, Leist M. 2011. TLR2 Hypersensitivity of astrocytes as functional consequence of previous inflammatory episodes. J Immunol 186:3237-3247.

Hinkle DA, Baldwin SA, Scheff SW, Wise PM. 1997. GFAP and S100beta expression in the cortex and hippocampus in response to mild cortical contusion. J Neurotrauma 14:729-738.

John GR, Lee SC, Song X, Rivieccio M, Brosnan CF. 2005. IL-1-regulated responses in astrocytes: Relevance to injury and recovery. Glia 49:161-176

Kamnasaran D, Hawkins C, Guha A. 2008. Characterization and transformation potential of "Synthetic" astrocytes differentiated from murine embryonic stem cells. Glia 56:457-470.

Kimelberg HK. 2004. The problem of astrocyte identity. Neurochem Int 45(2-3):191-202.

Kimelberg HK, Nedergaard M. 2010. Functions of astrocytes and their potential as therapeutic targets. Neurotherapeutics 7:338-353.

Kuegler PB, Zimmer B, Waldmann T, Baudis B, Ilmjärv S, Hescheler J, Gaughwin P, Brundin P, Mundy W, Bal-Price AK, et al. 2010 Markers of murine embryonic and neural stem cells, neurons and astrocytes: Reference points for developmental neurotoxicity testing. ALTEX 27:17-42.

Leist M, Single B, Castoldi AF, Kühnle S, Nicotera P. 1995. Intracellular adenosine triphosphate (ATP) concentration: A switch in the decision between apoptosis and necrosis. J Exp Med 185:1481-1486.

Leist M, Volbracht C, Kühnle S, Fava E, Ferrando-May E, Nicotera P. 1997. Caspase-mediated apoptosis in neuronal excitotoxicity triggered by nitric oxide. Mol Med 3:750-764.

Lotharius J, Falsig J, van Beek J, Payne S, Dringen R, Brundin P, Leist M. 2005. Progressive degeneration of human mesencephalic neuron-derived cells triggered by dopamine-dependent oxidative stress is dependent on the mixed-lineage kinase pathway. J Neurosci stress is depend

Lovatt D, Sonnewald U, Waagepetersen HS, Schousboe A, He W, Lin JH, Han X, Takano T, Wang S, Sim FJ, et al. 2007. The transcriptome and metabolic gene signature of protoplasmic astrocytes in the adult murine cortex. J Neurosci 27:12255-12266.

Lund S, Porzgen P, Mortensen AL, Hasseldam H, Bozyczko-Coyne D, Morath S, Hartung T, Bianchi M, Ghezzi P, Bsibsi M, et al. 2005. In hibition of microglial inflammation by the MLK inhibitor CEP-1347. J Neurochem 92:1439-1451.

J Neurochem 92:1439-1451.
Marini AM, Schwartz JP, Kopin IJ. 1989. The neurotoxicity of 1-methyl-4-phenylpyridinium in cultured cerebellar granule cells J Neurosci 9:3665-3672

Matyash V, Kettenmann H. 2010. Heterogeneity in astrocyte morphology and physiology. Brain Res Rev 63(1-2):2-10.

Meeuwsen S, Persoon-Deen C, Bsibsi M, Ravid R, van Noort JM. 2003. Cytokine, chemokine and growth factor gene profiling of cultured human astrocytes after exposure to proinflammatory stimuli. Glia 43:243-253

Mujtaba T, Rao MS. 2002. Isolation of lineage-restricted neural precursors from cultured ES cells. Methods Mol Biol 185:189-204. 
Nagai M, Re DB, Nagata T, Chalazonitis A, Jessell TM, Wichterle H, Przedborski S. 2007. Astrocytes expressing ALS-linked mutated SOD1 release factors selectively toxic to motor neurons. Nat Neurosci 10:615-622.

Nagelhus EA, Veruki ML, Torp R, Haug FM, Laake JH, Nielsen S, Agre P, Ottersen OP. 1997. Aquaporin-4 water channel protein in the rat retina and optic nerve: polarized expression in Müller cells and fibrous astrocytes. 18:2506-2519.

Napoli I, Kierdorf K, Neumann H. 2009. Microglial precursors derived from mouse embryonic stem cells. Glia 57:1660-1671.

Nedergaard M, Ransom B, Goldman SA. 2003. New roles for astrocytes: Redefining the functional architecture of the brain. Trends Neurosci 26:523-530

Pekny M, Levéen P, Pekna M, Eliasson C, Berthold CH, Westermark B, Betsholtz C. 1995. Mice lacking glial fibrillary acidic protein display astrocytes devoid of intermediate filaments but develop and reproduce normally. EMBO J 14:1590-1598.

Quinlan RA, Brenner M, Goldman JE, Messing A. 2007. GFAP and its role in Alexander disease. Exp Cell Res 313:2077-2087.

Reynolds BA, Weiss S. 1992. Generation of neurons and astrocytes from isolated cells of the adult mammalian central nervous system. Science 255:1707-1710.

Saura J. 2007. Microglial cells in astroglial cultures: A cautionary note. J Neuroinflammation 4:26.

Schildknecht S, Pöltl D, Nagel DM, Matt F, Scholz D, Lotharius J, Schmieg N, Salvo-Vargas A, Leist M. 2009. Requirement of a dopamiSchmieg N, Salvo-Vargas A, Leist M. 2009. Requirement of a dopami-
nergic neuronal phenotype for toxicity of low concentrations of 1-methyl-4-phenylpyridinium to human cells. Toxicol Appl Pharmacol 241:23-35.

Suárez I, Bodega G, Fernández B. 2002. Glutamine synthetase in brain: Effect of ammonia. Neurochem Int 41(2-3):123-142.
Suter DM, Cartier L, Bettiol E, Tirefort D, Jaconi ME, Dubois-Dauphin M, Krause KH. 2006. Rapid generation of stable transgenic embryonic stem cell lines using modular lentivectors. Stem Cells 24 $615-623$.

Vanhoutte N, de Hemptinne I, Vermeiren C, Maloteaux JM, Hermans E. 2004. In vitro differentiated neural stem cells express functional glial glutamate transporters. Neurosci Lett 370(2-3):230-235.

Volbracht C, Leist M, Nicotera P. 1999. ATP controls neuronal apoptosis triggered by microtubule breakdown or potassium deprivation. Mol triggered by micr

Med 5:477-489.
Volbracht C, Penzkofer S, Mansson D, Christensen KV, Fog K, Schildknecht S, Leist M, Nielsen J. 2009. Measurement of cellular beta-site of APP cleaving enzyme 1 activity and its modulation in neuronal assay systems. Anal Biochem 387:208-220.

Walz W. 2000. Controversy surrounding the existence of discrete functional classes of astrocytes in adult gray matter. Glia 31:95-103.

Walz W, Lang MK. 1998. Immunocytochemical evidence for a distinct Walz W, Lang MK. 1998. Immunocytochemical evidence for a distinct
GFAP-negative subpopulation of astrocytes in the adult rat hippocampus. Neurosci Lett 257:127-130

Wang DD, Bordey A. 2008. The astrocyte odyssey. Prog Neurobio 86:342-367.

Zhang MY, Kagan N, Sung ML, Zaleska MM, Monaghan M. 2008. Sensitive and selective liquid chromatography/tandem mass spectrometry methods for quantitative analysis of 1-methyl-4-phenyl pyridinium (MPP+) in mouse striatal tissue. J Chromatogr B Analyt Technol Biomed Life Sci 874(1-2):51-56.

Zimmer B, Kuegler PB, Baudis B, Genewsky A, Tanavde V, Koh W, Tan B, Waldmann T, Kadereit S, Leist M. 2011. Coordinated waves of gene expression during neuronal differentiation of embryonic stem cells as basis for novel approaches to developmental neurotoxicity testing. Cell Death Differ 18:383-395. 